*Pós-doutor na PUCRS; Doutor em Direito pela Unisinos; Mestre em Ciências Jurídico-Filosóficas pela Universidade de Coimbra; Especialista em Ciências Penais pela PUCRS; Professor da Faculdade e do Mestrado em Direito da UFPel. E-mail: uassam@gmail.com.

\section{Princípio Da Solidariedade Como Critério \\ De Aplicação do Princípio De Proibição De \\ Retrocesso Social Em Relação Aos Direitos \\ SOCIAIS}

Solidarity Principle As A Criterion For Applying The Principle Of Banning Social Regression In Relation To SOCIAL RightS

Der gute Jurist sieht im Gesetz weder das Ganze des Rechts noch ein Hindernis des Rechts, sondern ein Mittel zur

Verwirklichung des Rechts. 1

\section{Guilherme Camargo Massaú *}

Como citar: MASSAÚ, Guilherme Camargo. Princípio da solidariedade como critério de aplicação do princípio de proibição de retrocesso social em relação aos direitos sociais. Scientia Iuris, Londrina, v. 25, n. 1, p. 109-127, mar. 2021. DOI: 10.5433/21788189.2021v25n1p109. ISSN: 2178-8189.

Resumo: O texto versa sobre a relação do princípio da proibição do retrocesso social com o princípio da solidariedade, impresso no Art. $3^{\circ}$, I, in fine, da Constituição Federal (CF). Trata-se da aplicação do princípio da proibição do retrocesso em consonância com os parâmetros normativos estabelecidos pelos objetivos fundamentais do Estado brasileiro: construir uma sociedade solidária. Objetiva-se mostrar a densificação do sentido da vedação do emprego de medidas jurídicas socialmente retrocessivas por meio do princípio da solidariedade, inserido como cláusula transformadora. Para realizar a pesquisa, foram empregados os métodos analítico e hipotético-dedutivo. $\mathrm{O}$ primeiro foi utilizado visando esmiuçar as categorias jurídicas do princípio da proibição do retrocesso social e do princípio da solidariedade impresso na cláusula transformadora do Art. $3^{\circ}$, I, in fine, da CF. O segundo auxiliou na busca do resultado da incidência desses dois princípios assente em uma hipótese jurídica. Devido à natureza do tema e da pesquisa, utilizou-se de fontes bibliográficas.

Palavras-Chave: Constituição. Direitos fundamentais sociais. Princípios. Proibição de retrocesso social. Solidariedade. 


\begin{abstract}
This paper is about the relationship between the principle of social setback ban and the principle of solidarity, as written in the FC Art. 3, I, in fine. It deals with the application of the principle of setback ban stemming from the normative guidelines according to the main goals established by the Brazilian Government in order to build a solidary society. The objective is to show how dense the meaning of banning the use of judicial actions is, that can socially bring a setback originating from the solidarity specificities, inserted as a transformative clause. In order to carry out the research, analytical and hypotheticaldeductive methods have been used. The analytical method was used in order to scrutinize the judicial categories of social setback ban and solidarity principle found in the transformation clause of Art 3, I, in fine, of the FC. The hypothetical-deductive method helped in the search for results related to the incidence of those two principles from a judicial hypothesis based on bibliographical resources.
\end{abstract}

Keywords: Constitution. Fundamental social rights. Principles. Social regression prohibition principle. Solidarity. 


\section{INTRODUÇÃO}

O texto tem como objetivo analisar o princípio da solidariedade como critério de aplicação do princípio de proibição de retrocesso social. O esforço ora desenvolvido condiz com a cognoscibilidade do direito constitucional brasileiro vigente, tendo como referência medidas com efeitos prospectivos. Assim, o princípio de proibição de retrocesso social adquire eficácia protetiva, envolvendo os direitos sociais e o princípio da solidariedade.

Ambos os princípios objetos do texto possuem alto grau de abstração, o que dificulta a especificação e a generalização em casos concretos. Nessa perspectiva, entende-se que o mais oportuno para o objetivo proposto é trabalhá-los em patamar conceitual, contudo são dados exemplos pontuais para deixar claro o quê se analisa e como se está efetuando a análise. Outro fator de dificuldade é relativo aos objetivos fundamentais constantes na Constituição de 1988, pois são normas que, de certa forma, despertam pouco interesse ou são pouco invocadas, se comparadas com o vasto material publicado na seara jurídica.

Destaca-se, a título introdutório e de pré-compreensão do texto, o entendimento de que se tem como relativos aos direitos fundamentais e aos princípios normativos. Conforme o caso concreto, salienta-se um direito fundamental ou/e um princípio diante de outros. Esse tema mostra-se relevante, contemporaneamente, devido aos problemas sociais atuais, aliados ao cenário político-jurídico tendentes a reformas substanciais em direitos sociais, as quais recairão sobre os cidadãos. Salienta-se que, implicitamente, o texto foi analisado sem perder de vista os debates contemporâneos travados no âmbito do Estado brasileiro, o que oportuniza que a análise efetuada possa contribuir para soluções de problemas jurídicos.

Para que se pudesse chegar à consonância de incidência entre ambos os princípios, uma vez que o princípio da solidariedade densifica o da proibição de retrocesso social, foram percorridos alguns temas, a fim de estabelecer os parâmetros compreensivos concernentes à finalidade do texto. Primeiro, delineou-se o princípio de proibição de retrocesso social, ao mostrar de onde ele deriva e as condições de sua incidência. Após, passou-se para o princípio da solidariedade, explicitando-se o locus principal de sua positivação na Constituição e sua função no contexto normativo constitucional.

Por fim, foi desenvolvida a projeção unitária da incidência dos princípios analisados, no tocante à materialização da proibição retrocessiva social, em face da incidência simultânea do princípio da solidariedade como exigência normativa de se construir uma sociedade solidária. Portanto, ambos os princípios complementam-se em termos prospectivos.

\section{PRINCÍPIO DE PROIBIÇÃO DE RETROCESSO SOCIAL}

O princípio de proibição de retrocesso social encontra-se implícito na concepção lógica da Constituição brasileira. A ausência de sua menção explícita não lhe retira as consequências lógiconormativas que decorrem da incidência de algumas normas, sejam regras e/ou princípios ${ }^{1}$. Por 
conseguinte, cabe situá-lo a partir de elementos da Constituição de 1988 imediatamente vinculados à concepção da vedação do retrocesso social. Destaca-se, contudo, a impossibilidade de se defender de uma proibição absoluta de retrocesso social, justamente pelo fato de se reconhecerem as mudanças sociais pelas quais o Estado e a sociedade passam. É preciso, porém, que se tenha um mínimo de segurança jurídica em relação ao patamar de efetividade conquistado pelos direitos sociais (SARLET, 1999, p. 111-114).

\subsection{Lógica histórico-constitucional}

O desenrolar histórico-constitucional é um dos elementos que pode servir como (primeiro) fundamento para a consistência do princípio da proibição de retrocesso social. Cabe destacar que é relevante para sustentar a vedação de medidas retrocessivas no meio de avanços, estagnações e recuos sócio-políticos. Realça-se, nesse tópico, a particularidade do constitucionalismo de, a cada aperfeiçoamento pelas forças históricas, expandir e fortalecer as características de documentogarantia (VOLÄNDER, 1999, p. 7) dos cidadãos e dos indivíduos diante do Estado. Trata-se de reconhecer o desdobrar lógico das mudanças que derivaram inúmeros institutos positivados que, por conseguinte, conduziram à formulação do princípio da vedação de medidas retrocessivas que atinjam núcleos essenciais de direitos e garantias sociais.

A importância de assegurar direitos encontra-se na Déclaration des Droits de l'Homme et du Citoyen de 1789, no Art. $16^{2}$, onde se acentua a função da Constituição. O documento constitucional consolidou-se como pedra angular do Estado de Direito (democrático), por meio da força e da supremacia constitucionais (PINTO E NETTO, 2010, p. 116), adquiridas no decurso histórico com base em três realidades: a inglesa, que se inclinou ao governo balanceado e moderado, privilegiando a liberdade e a propriedade; a norte-americana, consistente em uma carta escrita por um poder constituinte que garante direitos e regulamenta o governo com freios $e$ contrapesos; a francesa, baseada na ideia de ruptura criadora, a qual foi de encontro aos privilégios do ancien régime e define projetos de ordenação para uma nova ordem racionalmente construída (CANOTILHO, 2002, p. 52-53).

Essas conquistas históricas constitucionalmente são intangíveis ao ato de supressão. Todas elas representam o fortalecimento de garantias aos indivíduos (em sentido geral) frente ao Estado, sendo que a extinção ou o enfraquecimento ao ponto de torná-las ineficazes representa uma ruptura nas bases do constitucionalismo. Suprimi-las é ato revolucionário. Assim, historicamente, encontram-se os direitos sociais fundamentais, uma vez que sua constitucionalização se originou de embates e de reivindicações dentro do contexto das relações sociais. O princípio de proibição de retrocesso social corrobora, em sua lógica, conquistas históricas, como as citadas, ao vedar imposições do Estado que anulem o núcleo essencial dos direitos sociais.

O constitucionalismo desenvolvido nos últimos séculos acarretou a identificação dos

as respectivas características, vide: Derbli (2007, p. 106-109).

2 “Toute Société dans laquelle la garantie des Droits n'est pas assurée, ni la séparation des Pouvoirs déterminée, n'a point de Constitution" (A sociedade que não assegurar a garantia dos direitos nem determinada a separação de poderes, não tem constituição - tradução livre do autor) (FRANÇA, 1789; SILVA, 2011; VOLÄNDER, 1999). 
cidadãos com o projeto de comunidade político-social do Estado ao qual pertencem (SILVA, 2011, p. 11). Por isso, elementos constitucionais, introduzidos por força de movimentos históricos, merecem maior proteção do que aqueles resultantes de deliberações políticas circunstanciais. É necessário reconhecer a coerência do desenrolar temporal que resultou no sistema constitucional atual. Os direitos sociais não se encontram na Constituição Federal (CF) por mera deliberação política circunstancial, mas por redundarem em opção pertinente e importante de avanço social no Estado brasileiro.

O desenrolar histórico constitucional culminou, contemporaneamente, em consequências, nas quais o princípio de proibição de retrocesso social logicamente se apoia: 1) o princípio do Estado direito social necessita de um patamar mínimo de proteção da confiança, de segurança jurídica (CANOTILHO, 2002, p. 257) e de manutenção mínima do nível de continuidade jurídica, por isso, medidas sociais retrocessivas e retroativas causam enfraquecimento e contradizem o Estado de Direito social; 2) o princípio da dignidade humana exige do aparato estatal prestações sociais positivas, a fim de garantir o mínimo de existência com dignidade, por conseguinte o efeito negativo desse princípio é a exigência de que medidas não fiquem aquém do patamar considerado como mínimo; 3) o princípio da máxima eficácia e efetividade das normas de direitos fundamentais (Art. $5^{\circ}, \S 1^{\circ}$, da $\mathrm{CF}$ ) indica a exigência de maximização e a não redução da proteção dos direitos fundamentais; 4) a insuficiência de proteção que o princípio da segurança jurídica do Art. $5^{\circ}$, XXXVI, da CF pode oferecer aos direitos fundamentais sociais; 5) a vinculação dos órgãos estatais às normas constitucionais e a seus atos anteriores (princípio da confiança), que faz com que os órgãos do Estado mantenham sua autonomia, sem, contudo, perderem como fundamento de suas ações as normas constitucionais, sem as quais as decisões tomadas pelos órgãos podem estar em direto desrespeito constitucional (PINTO E NETTO, 2010, p. 115, 135-136; SARLET, 2015, p. 464-466). Tais consequências são respostas históricas, político-jurídicas decorrentes de opressões, violações e injustiças socialmente situadas. Por conseguinte, os direitos fundamentais são de realizações inacabadas (NOVAIS, 2015, p. 71).

Com as conquistas constitucionais na seara social com vistas à justiça social (SARLET, 2015, p. 456-457), surge o dever de realização progressiva dos direitos sociais, tal como ocorreu e ainda, com menor necessidade, ocorre com os direitos de liberdade. Admitir medidas retrocessivas que anulem essas conquistas implica desprezar o Estado social e alguns dos objetivos constitucionais (e. g. Art. $\left.3^{\circ}\right)$.

\subsection{Limites à reforma constitucional}

O limite material (SARLET; BRANDÃO, 2013, p. 1129-1131) à reforma constitucional estabelecido no Art. $60, \S 4^{\circ}$, da CF - as chamadas cláusulas pétreas - veda a abolição do núcleo essencial, material dos conteúdos normativos da forma federativa de Estado: o voto direto, secreto, universal e periódico; a separação dos poderes; os direitos e as garantias individuais. O sentido normativo do dispositivo constitucional não veda modificações, inclusive restrições à esfera de incidência, mas a supressão do núcleo essencial (SARLET; MARINONI; MITIDIERO, 2017, p. 
156-160).

Embora a literalidade do Art. $60, \S 4^{\circ}$, IV, da CF infira a exclusão dos direitos sociais do âmbito da proteção das cláusulas pétreas, no que tange ao sistema constitucional como pedra angular do sistema jurídico que é unitário, adota-se, nesse texto, a posição majoritária da doutrina e a inclinação do Supremo Tribunal Federal em incluir os direitos sociais - e os demais capítulos do Título II da CF - no raio de proteção material das cláusulas pétreas (SARLET; BRANDÃO, 2013; SARLET; MARINONI; MITIDIERO, 2017; SARLET, 2015).

Com a vedação de abolir conteúdos que atribuem identidade à Constituição brasileira, temse aí uma expressa vedação de retrocesso considerando-se o núcleo constitucional. Destarte, o princípio da proibição de retrocesso social constitui-se em um limite normativo ao Poder Legislativo e um critério normativo ao Poder Judiciário. Some-se a isso o Art. $2^{\circ}, 1$, do Pacto Internacional sobre direitos econômicos, sociais e culturais - internalizado pelos Decretos Legislativo n. 226/91 e Presidencial n. 591/92 (BRASIL, 1992) - o qual traz o compromisso de os Estados signatários progressivamente (SARLET; MARINONI; MITIDIERO, 2017, p. 619) empregarem meios apropriados e recursos disponíveis para que os indivíduos exerçam os direitos constantes no Pacto. A palavra progressivamente impede que se aceite o estabelecimento de normas que causem retrocesso nas conquistas já estabelecidas (SARLET; MARINONI; MITIDIERO, 2017, p. 390).

\section{Segurançajurídica}

O princípio da segurança jurídica constitui-se em uma das formas de densificação do princípio da proibição de retrocesso social, embora seus conteúdos não se confundam (DERBLI, 2007, p. 213-217) totalmente. Mencionado no Preâmbulo, no caput dos $5^{\circ}$ e $6^{\circ}$ da CF e especificado no Art. $5^{\circ}$, XXXVI, da CF (SARLET, 2015, p. 452), o princípio da segurança jurídica oferece estabilidade à ordem jurídica, especialmente ao núcleo essencial dos direitos sociais, fazendo com que o indivíduo e a sociedade (como grupo de indivíduos) possam estabelecer relações entre si e com o Estado, assentes em parâmetros tutelados pela proteção da confiança ${ }^{3}$, tendo como base estrutural à segurança jurídica a cognoscibilidade ${ }^{4}$, a confiabilidade ${ }^{5}$ e a calculabilidade . $^{6}$.

Destarte, pela consolidação do pensamento constitucional, tem-se o Estado de Direito como manifestação de um Estado de segurança jurídica (HESSE, 1993, p. 206). Trata-se de subprincípio de categoria estruturante do Estado de Direito que perpassa os direitos fundamentais

3 Sachs a denomina de echte Rückwirkung, tratando-a como um retrocesso que abrange relações jurídicas consolidadas no tempo e que não podem ser alteradas por serem perfeitas. E denomina de unechte Rückwirkung medidas retrocessivas que reduzem garantias e direitos conquistados, sem, no entanto, atingir o ato jurídico perfeito, a coisa julga e os direitos adquiridos. (SACHS, 2000; HESSE, 1993; DERBLI, 2007).

4 Não se adentrará na análise dessas três categorias, cabe aqui especificá-las. A cognoscibilidade reporta a um estado de coisas em que os indivíduos se encontram capacitados a compreenderem os argumentos normativos gerais e individuais, materiais e procedimentais, tendo em vista a acessibilidade, a abrangência, a clareza, a determinabilidade e a executoriedade. (ÁVILA, 2011, p. 683).

5 A confiabilidade consiste em um estado ideal que o indivíduo pode vir a saber quais são as possíveis mudanças a serem feitas e as que não podem. Evita-se, portanto, a frustração dos seus direitos, na perspectiva de que hoje os indivíduos se asseguram dos efeitos dos direitos garantidos outrora. (ÁVILA, 2011, p. 863).

6 A calculabilidade é a possibilidade de os indivíduos saberem como e quando as mudanças podem ser feitas, o que impede a surpresa. Ela existe diante da possibilidade do controle dos efeitos atribuídos pelo direito atual no futuro. Assim, deve existir a possibilidade de antecipar e medir as consequências a serem aplicadas a fatos ou atos. (ÁVILA, 2011, p. 684). 
para evitar que deságue em inclinações despóticas (SARLET, 2015, p. 451), assim, ao impedir medidas retrocessivas de direitos adquiridos, garante-se um nível de estabilidade ${ }^{7}$ para viver e agir sem medo ou insegurança no âmbito social e estatal (SARLET; MARINONI; MITIDIERO, 2017; SARLET, 2015; PINTO E NETTO, 2010).

Por conseguinte, o princípio da segurança jurídica abrange a segurança pessoal e social, protegendo a pessoa e/ou grupo de pessoas contra atos do poder público ou de particulares que violem direitos e garantias pessoais e/ou sociais com medidas retroativas (contra direitos adquiridos, coisa julgada e ato jurídico perfeito). Contudo, sustenta-se também que o princípio da segurança jurídica incide contra as medidas retrocessivas de caráter prospectivo. Nesse talante, não se admitem reformas constitucionais ou infraconstitucionais que revoguem, suprimam ou anulem núcleos essenciais de normas materiais de direitos sociais regulamentados por dispositivos constitucionais ou infraconstitucionais, mesmo com efeitos prospectivos (SARLET, 2015, p. 452, 453), que já integram o patrimônio ${ }^{8}$ do indivíduo e do grupo de indivíduos. Portanto, o princípio da segurança jurídica encontra-se logicamente atrelado ao princípio da proibição do retrocesso, concretizado por meio de barreira de redução de conteúdo material de direitos e de garantias em termos de acesso aos direitos sociais - de dimensão positiva e negativa.

\subsection{Repercussões na eficácia e efetividade}

Recai na eficácia e na efetividade das regras e princípios de direitos sociais a proibição de medidas retrocessivas, já que o Art. $5^{\circ}, \S 1^{\circ}$, da CF atribui aplicação imediata. As normas de direitos sociais não podem ser esvaziadas em sua dimensão de aplicabilidade. Mantém-se, assim, a eficácia. A vedação do retrocesso assume, portanto, uma eficácia 'protetiva' dos direitos sociais (SARLET, 2015, p. 455, 466). Como consequência, na dimensão defensiva ligada ao princípio da dignidade da pessoa humana, a proibição de medidas retrocessivas tem a finalidade de garantir a efetividade de níveis de proteção concretizados nas normas de direitos sociais existentes, fundamentalmente no que tange às garantias mínimas de existência digna (SARLET; MARINONI; MITIDIERO, 2017, p. 620).

Por consequência, as prestações básicas correspondentes ao mínimo existencial não podem ser suprimidas ou reduzidas, inclusive se ressalvados os direitos adquiridos, sob pena de se ferir o princípio da proibição de retrocesso no que diz respeito a medidas que garantam, em certo grau, a efetivação do núcleo essencial da dignidade da pessoa humana. Se determinados níveis de proteção

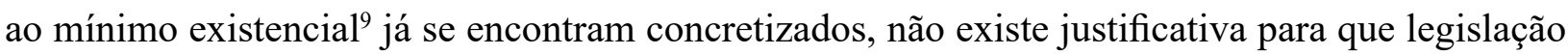

7 A fim de destacar a importância do tema da segurança jurídica, registra-se a existência do seguinte estudo: Fontes (2013, p. 20-22, 34). Em rápido resumo, o autor chama a atenção para a importância da estabilidade do direito e da estabilidade social que o direito proporciona no cotidiano dos indivíduos. Segundo Fontes, os direitos políticos, econômicos, sociais e culturais visam à estabilidade. São direitos que se encontram, de certa maneira, de modo uniforme nas constituições ocidentais. Logo, a estabilidade constituída não pode ser enfraquecida por qualquer redução transitória da capacidade financeira. Os bens jurídicos protegidos por essa gama de direitos constituem, em seu núcleo essencial, suporte necessário para a materialização da dignidade humana, que não é traduzível em valor patrimonial.

8 Entenda-se a palavra patrimônio no sentido empregado por Sarlet (1999, p. 111-132).

9 Para Derbli (2007, p. 210), seria redundante vincular a proibição do retrocesso social exclusivamente ao mínimo existencial, devido à proteção e à promoção da dignidade humana. Nessa lógica, incidirá a proibição do retrocesso 
superveniente suprima ou reduza posições sociais adquiridas. Por isso, tornam-se juridicamente injustificáveis medidas retrocessivas, podendo o Poder Judiciário considerá-las inconstitucionais (SARLET; MARINONI; MITIDIERO, 2017, p. 620). Não se trata da impossibilidade de revogação ou alteração de lei, no entanto, quando isso ocorrer, o legislador deve substituir ou alterar a lei por disposições de garantias e de direitos de igual ou maior grau de proteção do que as anteriores (DERBLI, 2007, p. 281-283).

Aqui se situa, contudo, uma objeção à proibição de retrocesso, pois ela se direciona à competência do legislador. Ela se refere à falta de conteúdo específico dos direitos sociais na Constituição. Essa indeterminabilidade faria com que o legislador tivesse ampla liberdade de conformação de tais direitos fundamentais. Isso englobaria inclusive a possibilidade de retroceder nas próprias decisões, embora o legislador esteja limitado pelo princípio da proteção da confiança, pela imprescindibilidade de justificar as medidas reducionistas e pela intangibilidade do núcleo essencial dos direitos fundamentais. Essa objeção, no que diz respeito à afetação do núcleo essencial dos direitos sociais, não prospera. Em primeiro lugar, existe a proteção contra mudanças formais constitucionais. Não se pode, portanto, anular o núcleo essencial dos direitos fundamentais (SARLET, 2015, p. 461-462).

Em segundo lugar, o legislador constitucional derivado e infraconstitucional está vinculado às normas constitucionais, pois, ao legislar com o intuito de concretizá-las, não pode, posterior e simplesmente, desfazer o que realizou no cumprimento de mandamento constitucional ${ }^{10}$. Se isso for admitido, a eficácia e a efetividade constitucionais - fundamentalmente no que se refere ao núcleo essencial dos direitos sociais, vinculado ao mínimo existencial - ficariam a critério do legislador constitucional derivado e do infraconstitucional, subvertendo o comando do próprio legislador que instauraria uma situação social favorável e, depois, conforme seu arbítrio e sua oportunidade, substituiria a situação favorável por uma desfavorável (ou menos favorável) (SARLET, 2015, p. $462-463)^{11}$.

Assim, entende-se que, depois de conquistado determinado grau de realização de direitos sociais, eles passam a constituir garantia institucional, logo tornam-se direitos subjetivos, limitando em grau a retrocessão de direitos adquiridos. Caso se admitisse que medidas retrocessivas pudessem atingir o núcleo essencial de direitos fundamentais sociais, se estaria, igualmente, ferindo o princípio da proteção da confiança, o da segurança jurídica e o mínimo existencial que sustenta a concretização da dignidade humana (CANOTILHO, 2002, p. 336-337).

\section{PRINCÍPIO DA SOLIDARIEDADE}

O princípio da solidariedade ${ }^{12}$ encontra-se inserido no Art. $3^{\circ}$, I, in fine, da CF. Ele se

social em grau acima do mínimo existencial, a fim de impedir o retrocesso da concretização dos direitos sociais, mesmo que não abranjam prestações mínimas indispensáveis à manutenção do grau mínimo de dignidade humana. (PINTO E NETTO, 2010, p. 135).

10Uma crítica à aplicação do princípio da proibição de retrocesso, quando de recriação de omissão constitucional (DERBLI, 2007, p. 259-268).

11 Opinião contrária de tal impeditivo (ANDRADE, 1987; CANOTILHO, 2002; DERBLI, 2007).

12 Para a perspectiva histórica da construção do princípio da solidariedade (MASSAÚ, 2016, p. 33-58). 
manifesta como objetivo fundamental do Estado constitucional brasileiro, por meio da chamada cláusula transformadora, cujo objetivo é impelir o Estado a promover mudanças na estrutura socioeconômica da sociedade (BERCOVICI, 2005, p. 36-37), ver: (VERDÚ, 2004; VOLÄNDER, 1999). O princípio da solidariedade encontra-se previsto expressamente em várias constituições ${ }^{13}$, pode-se também encontrá-lo implicitamente em alguns parâmetros institucionais que o exigem para seu desenvolvimento. Destaca-se que a solidariedade se origina do mesmo espírito dos direitos humanos. Ela participou da revolução constitucional do século XVIII, institucionalizando-se com o desenvolvimento do Estado-nação republicano sob o viés do welfare state e com os movimentos sociais dos séculos XIX-XX (SCHOLZ, 2014, p. 49).

A previsão implícita ${ }^{14}$ do princípio da solidariedade não é aqui objeto de análise, e sim sua manifestação no texto constitucional brasileiro.

\subsection{Morfologia Dos Objetivos Fundamentais}

O Art. $3^{\circ}$ da $\mathrm{CF}$ (objetivos fundamentais) é peculiar na história constitucional pátria. Ele impõe ao Estado brasileiro objetivos qualificados de fundamentais. Trata-se do anseio de transformação do legislador originário que estabeleceu, como diretriz constitucional, a cláusula

13 Dentre 192 constituições, 91 apresentam a palavra solidariedade e/ou fraternidade. Esse número resultou de pesquisa realizada no sítio www.constituteproject.org/search?lang=en\&key=solid\&status=in_force, em 02/01/2018. As palavras-chave utilizadas foram fraternity e solidarity. Elas estão em inglês devido ao fato de o sítio ser em inglês. Embora o sítio tenha localizado 91 constituições, nem todas citavam expressamente as palavras-chave. Por isso, o número de constituições citadas é menor. Também não se citou constituições que empregavam as palavras-chave como princípios das relações internacionais dos respectivos Estados. As seguintes constituições empregam uma ou as duas palavras-chave: Albania 1998 (Preamble), Algeria 1989 (Preamble, Art. 30), Angola 2010 (Preamble, Art. 1), Argentina 1853 (Art. 75), Armenia 1995 (Preamble), Austria 1920 (Art. 14, 5a), Bahrain 2002 (Art. 4), Bangladesh 1972 (Art. 9), Belgium 1831 (Art. 7 Bis), Benin 1990 (Preamble, Art. 153), Bhutan 2008 (Art. 8, 3), Bolivia 2009 (Preamble, Art. 8), Burundi 2005 (Preamble, Art. 267), Cameroon 1972 (Preamble, Art. 55, 4), Chad 1996 (Preamble), Chile 1980 (Art. 3, Art. 115), Colombia 1991 (Art. 1, Art. 48, Art. 49, Art. 95, Art. 356, Art. 367), Comoros 2001 (Preamble, Art. 1, Art. 11), Congo 2005 (Preamble), Costa Rica 1949 (Art. 64, Art. 74), Côte d'Ivoire 2016 (Preamble), Cuba 1976 (Art. 12, h), Djibouti 1992 (Preamble), Dominican Republic 2015 (Preamble, Art. 75, 10, Art. 196, Art. 217), Ecuador 2008 (Preamble, Art. 27, Art. 32, Art. 34, Art. 66, 15, Art. 83, 9, Art. 85, 1, Art. 95, Art. 238, Art. 270, Art. 283, Art. 340, Art. 355, Art. 367, Art. 395, 5), Egypt 2014 (Art. 8), Equatorial Guinea 1991 (Art. 17), Eritrea 1997 (Preamble, Art. 9), Ethiopia 1994 (Art. 88, 2), France 1958 (Preamble, Art. 2, Art. 72, 2, Art. 87), Gabon 1991 (Art. 1, 20), Greece 1975 (Art. 25, 4), Guatemala 1985 (Art. 151), Guinea 2010 (Art. 1), Haiti 1987 (Art. 4), Honduras 1982 (Art. 15), Hungary 2011 (Art. XIX), Italy 1947 (Art. 2), Korea (Democratic People's Republic) 1972 (Art. 17, Art. 81), Kuwait 1962 (Art. 25), Latvia 1922 (Preamble), Macedonia 1991 (Art. 8), Madagascar 2010 (Preamble, Art. 19, Art. 140), Mauritania 1991 (Art. 9), Mexico 1917 (Art. 3, II, c), Morocco 2011 (Preamble, Art. 40, Art. 93, Art. 136, Art. 140, Art. 142, Art. 146), Mozambique 2004 (Art. 20, Art. 44), Myanmar 2008 (Preamble, 6b, 20e, 22b, 40c, 65, 365, 383b, 404c, 417), Namibia 1990 (Preamble), Nepal 2015 (Preamble, 50 , 2, b), Nicaragua 1987 (Art. 3, Art. 4, Art. 5, Art. 6, Art. 60, Art. 73), Niger 2010 (Art. 1, Art. 3, Art. 158, Art. 165, Art. 172), Oman 1996 (Art. 12), Pakistan 1973 (Preamble), Panama 1972 (Art. 91), Paraguay 1992 (Art. 73), Peru 1993 (Art. 14), Philippines 1987 (Art. XV, 1), Poland 1997 (Preamble, Art. 20), Portugal 1976 (Art. 63, Art. 66, 2, Art. 71, Art. 73, Art. 225, Art. 227, 1, j), Qatar 2005 (Art. 20), Romania 1991 (Art. 46), Sao Tome and Principe 1975 (Art. 1), Senegal 2001 (Preamble), Seychelles 1993 (Preamble), Solomon Islands 1978 (Preamble), South Sudan 2011 (Art. 46, 2, b), Spain 1978 (Preliminary Title, Sec 2, Part I, Chap. 3, Sec. 45, Part. VIII, Chap. 3, Sec. 156), Sudan 2005 (23, 2, b), Switzerland 1999 (Preamble), Syrian Arab Republic 2012 (Art. 14, Art. 24), Tanzania 1977 (Part. II, 9), Thailand 2017 (Preamble, 164, 4, 257, 1), Timor-Leste 2002 (Preamble), Togo 1992 (Art. 142), Tunisia 2014 (Preamble, Art. 136), Turkey 1982 (Art. 2, Art. 136), United Arab Emirates 1971 (Art. 14), Vanuatu 1980 (7, f), Venezuela 1999 (Preamble, Art. 2, Art. 4, Art. 75, Art. 84, Art. 123, Art. 152, Art. 274, Art. 299, Art. 326), Vietnam 1992 (Preamble, Art. 5, Art. 9, Art. 60), Yemen 1991 (Art. 25). Destaca-se que a citação dos dispositivos com as respectivas constituições não pressupõe que eles possuem a mesma função normativa do Art. $3^{\circ}, \mathrm{I}$, da $\mathrm{CF}$, até porque essa perspectiva não foi analisada. Os nomes dos países estão em inglês para facilitar a consulta ao sítio.

14 Ela é citada quando sua perspectiva implícita se torna necessária para sustentar o argumento que se está desenvolvendo na análise no texto. O fato de o indivíduo viver em sociedade atribui-lhe deveres de solidariedade para com os outros e para com a sociedade (ANDRADE, 1987, p. 86). 
de transformação expressa no modelo de uma constituição dirigente (BERCOVICI, 2005, p. 37) ${ }^{15}$. Tem-se, como consequência da imposição normativa dos objetivos fundamentais, a necessidade de os três poderes aplicarem as normas constitucionais de acordo com os objetivos expressos. Se as aplicarem de forma a contrariá-los, se estará diante de uma inconstitucionalidade.

\subsubsection{Cunho programático}

Por conterem objetivos a serem constantemente perseguidos, as normas do Art. $3^{\circ}$ da $\mathrm{CF}$ possuem cunho programático (SARLET, 2015, p. 454-455), impondo o dever de o Estado remover os obstáculos de ordem social que restrinjam a liberdade e a igualdade (APOSTOLI, 2012, p. 9). Elas impõem finalidades nas quais, no entanto, não se identificam limites, e.g., do texto normativo do Art. $3^{\circ}$, I, da CF não se têm meios de saber o quantum de uma sociedade livre, justa e solidária precisa-se para concretizar a norma. Com a vênia técnica, não há liquidez a ser medida na sua concretização.

O sentido normativo dos objetivos fundamentais é criar o dever de que, em a cada atuação do Estado - pode-se também pensar no âmbito privado -, os objetivos previstos estejam presentes, quando for possível, no sentido de enfraquecer as barreiras de convivência social. Tal exigência surgiu depois da Segunda Grande Guerra com o Estado social (APOSTOLI, 2012, p. 10, 18). Somente a presença dos objetivos fundamentais na atuação é capaz de fazer com que eles se densifiquem ao ponto de identificar um mínimo de concretização dos objetivos ${ }^{16}$, e.g., diante do texto normativo do Art. $3^{\circ}$, I, da CF é preciso que a norma tenha elementos conducentes a uma sociedade livre, justa e/ou solidária. Se nela estiverem presentes elementos opostos, não se concretizarão os objetivos fundamentais ${ }^{17}$.

\subsubsection{Alta densidade normativa ${ }^{18}$}

Embora se identifique o cunho programático - genérico em relação às demais normas programáticas ou de baixa densidade normativa -, é preciso ressaltar que os objetivos fundamentais são normas aplicáveis imediatamente, que independem de ulterior restringibilidade do legislador. Eles possuem alta densidade normativa, pelo fato de que, para serem concretizados, é preciso que,

15 Em tal sentido, tem que se classificar a Constituição brasileira como dirigente, pois no caso do Art. $3^{\circ}$ da $\mathrm{CF}$, o legislador constituinte define fins e estabelece programas a serem respeitados (CANOTILHO, 1994, p. 12). Não se adentra a problemática da constituição dirigente, mas como revisão crítica de seu próprio pensamento (CANOTILHO, 2006; DERBLI, 2007).

16 Nota-se que o cunho programático é diferente, e.g., do Art. 37, VII, da CF. No caso do direito de greve do servidor público, o objeto e o objetivo estão definidos. Tanto que, sem a regulamentação legislativa, o Supremo Tribunal Federal reconhece aplicabilidade imediata do direito de greve do servidor público e o equivale, de forma análoga e no que é possível, ao direito de greve do setor privado (Lei n. 7.783/89). Destaca-se que, quando o direito de greve do servidor público está regulamentado, o legislador ordinário deve observar os objetivos do Art. $3^{\circ}$ da $\mathrm{CF}$, assim como o Supremo Tribunal Federal deve observar, mesmo que implicitamente, os objetivos fundamentais ao julgar a lacuna infraconstitucional (LEITE, 2013, p. 847-848).

17 Os objetivos fundamentais expressam a vontade (diga-se: normativo-axiológica) do legislador constituinte. Por isso, parte-se do pressuposto de se ter a vontade de concretizar a constituição - especificamente seus objetivos -, contudo, parafraseando Jaspers, é preciso indagar se realmente se quer ou não esse Estado (projetado pelos objetivos) (JASPERS, 1966, p. 23). Ver em Freitas (2010, p. 28).

18 Classificação de Sarlet (2015, p. 260-261). 
em cada constituição de norma, haja a presença do conteúdo dos objetivos. Por conseguinte, o texto normativo do Art. $3^{\circ}$ da $\mathrm{CF}$ torna-se critério interpretativo para todos que aplicarem as normas constitucionais e infraconstitucionais - pelo critério hierárquico. Trata-se, todavia, de um critério normativo, uma vez que, a cada interpretação, devem ser levados em consideração os objetivos possíveis de serem concretizado no caso específico ${ }^{19}$.

Destarte, cada norma extraída de texto normativo deve apresentar algum grau de densidade de um ou de alguns dos objetivos fundamentais. $\mathrm{O}$ aplicador do direito, entre das interpretações possíveis, deve optar por aquela que se incline aos incisos do Art. $3^{\circ}$ da CF. A aplicação da norma extraída do texto dos objetivos fundamentais dá-se no encontro da norma a ser aplicada ao caso concreto com a incidência dos objetivos fundamentais.

Por consequência, defende-se a vedação de delimitação e definição normativa do conteúdo dos objetivos do Art. $3^{\circ}$ da CF por parte do legislador ordinário, sob pena de restringir o âmbito interpretativo-finalista dos objetivos fundamentais. Nesse caso, estaria vedada a redução de conteúdo a ser compreendido dos objetivos constitucionais.

\subsection{Extração do princípio da solidariedade}

O princípio da solidariedade não está expresso na $\mathrm{CF}$, mas é consequência lógico-normativa do Art. $3^{\circ}$, I, in fine, da CF, do Estado social e do viver em sociedade e em um Estado (GIUFFRÈ, 2002). No inciso primeiro do Art. $3^{\circ}$, encontram-se três objetivos(-princípios): a construção de uma sociedade livre, de uma sociedade justa e de uma sociedade solidária. Esses três princípios concretizados juntos constituem o objetivo, embora a opção por um na impossibilidade dos demais seja normativamente aceita. Separam-se esses três valores justamente pelo fato de eles não se confundirem. Uma sociedade livre pode não levar em consideração, necessariamente, a justiça nem a solidariedade. Assim, a mesma situação pode ocorrer conforme a compreensão de justiça e de solidariedade.

Logo, o princípio da solidariedade é retirado do objetivo da construção de uma sociedade solidária. Para que se concretizem os objetivos fundamentais do Estado brasileiro, é necessário que, em cada concretização normativa, encontre-se algum grau de densidade dos objetivos, aqui traduzido em princípio, já que do objetivo é preciso retirar uma norma. Para completar o processo de interpretação e aplicação do princípio da solidariedade, resta estabelecer o que é ou não conteúdo que expressa o objetivo fundamental. No entanto, delimitar o conteúdo da solidariedade não é a finalidade do texto ${ }^{20}$.

\subsection{Suporte fático do princípio da solidariedade (Art. $3^{\circ}$, I, da CF)}

O suporte fático que contém o princípio da solidariedade diz respeito à parte final do inciso I. O texto normativo que remete à solidariedade tem o seguinte enunciado: Constituem objetivos fundamentais da República Federativa do Brasil: I - construir uma sociedade [...] solidária. 
O texto constitucional em análise divide-se em duas partes. A primeira, o caput, condiz com a declaração de que os incisos que se seguem ao caput trazem (constituem) os objetivos fundamentais constitucionais do Estado brasileiro. A segunda, o inciso I, no referente à sociedade solidária, apresenta o verbo (construir) no infinitivo. Assim, o dispositivo normativo tem a seguinte leitura: constitui-se em objetivo fundamental da República Federativa do Brasil construir uma sociedade solidária.

Nessa frase do dispositivo normativo constitucional, têm-se duas orações: 1) a finita: constitui-se em objetivo fundamental da República Federativa do Brasil construir uma sociedade solidária; 2) a não finita: construir uma sociedade solidária. Por conseguinte, a não finita é uma oração subordinada infinitiva, exercendo a função de sujeito, sendo uma oração subordinada, substantiva, infinitiva, subjetiva. Salienta-se que o verbo do caput está conjugado no presente do indicativo, referindo-se à existência dos valores fundamentais listados nos incisos do Art. $3^{\circ}$ da CF. Acrescenta-se que a oração subordinada, substantiva, infinitiva, subjetiva remete ao sujeito construção de sociedade solidária. Por conseguinte, a referência normativa do texto constitucional em análise adquire um significado de imperativa existência do valor solidário na construção da sociedade, resultando no objetivo de formação de uma sociedade solidária.

O texto normativo do qual se aduz o princípio da solidariedade proporciona ao intérprete/ aplicador do direito critérios valorativos para estabelecer posição mediante o caso concreto, pois impõe uma ação (ZAGREBELSKY, 2002, p. 110, 118). No entanto, seu conteúdo não pode ser determinado com a incidência somente do sentido normativo, extraído do Art. $3^{\circ}$, I, da $\mathrm{CF}$, requerendo também o sentido do contexto histórico-constitucional axiológico a determinar o conteúdo pragmático da situação jurídico-subjetiva (APOSTOLI, 2012, p. 23), devido à sua vagueza $^{21}$; embora se possam determinar limites de sentido (LUZZATI, 1990, p. 42) do que é ou não solidário, muitas possibilidades encaixam-se no que é ou não considerado solidário. Nesse espaço, o interprete/aplicador do Direito pode utilizar discricionariedade no momento da tomada de decisão. Por conseguinte, deve-se ter, no horizonte, dois tipos de significados: a) o das expressões isoladas de um paradigma abstrato aplicável a uma série ilimitada de casos possíveis; b) aquele que, entre diversos potenciais significados, advém, de forma concreta, na expressão linguística do texto constitucional, em conformidade com o contexto no qual há o ato de proferir o significado (LUZZATI, 1990, p. 43) ${ }^{22}$.

Por se constituir em norma-princípio constitucional, é preciso reconhecer a manifestação de dois princípios inerentes ao sistema constitucional: a força normativa da constituição, que vincula, reciprocamente, o conjunto de normas jurídicas constitucionais com a realidade político-

21 A vagueza tem como característica as delimitações do significado. A área de aplicação da expressão linguística não está precisamente delimitada. Com isso, passam a existir casos limites, aos quais não se sabe se o dispositivo interpretado é aplicável ou não (LUZZATI, 1990, p. 47, 51).

22 Como forma de estabelecer o conteúdo do significado de solidariedade, conjuntamente com o caso concreto, é preciso ter a compreensão do que hodiernamente se considera solidariedade. Para isso, e.g., vide as sete teses sobre a solidariedade hoje em Zoll (2000, p. 119). É necessário ainda delimitar normativamente o espectro do suporte fático que envolve o princípio da solidariedade. Pode-se assim encaixar o conteúdo material no quadro do suporte fático. Para que isso ocorra, é essencial levar-se em consideração a expressão da solidariedade para o Direito, e.g., vide: Piazolo (2004, p. 177-224); vide: Massaú (2016, p. 87-127). 
social (HESSE, 1993, p. 28), a fim de aperfeiçoar a concretização da norma; a supremacia da constituição, que leva os Poderes do Estado a atuarem em conformidade com as normas constitucionais (HESSE, 1993; PINTO E NETTO, 2010, p. 116, 119). Esses dois princípios incidem na direção da concretização constitucional, conformando a ação e reprovando a omissão dos Poderes constituídos no que se refere ao paradigma constitucional.

\section{DIMENSÃO FUTURA: EFEITO PROSPECTIVO}

Concebe-se, como um pressuposto apoiado em doutrina e jurisprudência, a aplicação de um regime geral e, em princípio, unificado, para os direitos fundamentais de categorias dogmáticas envolvendo limites e restrições, assim como para os direitos sociais, que os afetam em suas dimensões objetiva e subjetiva, o que implica controlar a legitimidade constitucional das restrições e das limitações aos direitos sociais. Ao reconhecer isso, independentemente da aceitação da aplicação do princípio da proibição de retrocesso social, é inerente ao Estado constitucional de Direito que os direitos fundamentais, inclusive os direitos sociais, não estejam totalmente disponíveis aos poderes constituídos. Embora não existam direitos absolutamente irrestringíveis, os direitos sociais encontram-se também sob a reserva dos limites aos limites (Schranken-Schranken) (SARLET; MARINONI; MITIDIERO, 2017, p. 619, 620). Há que se incluir o princípio da primazia da constituição, o qual exige que normas infraconstitucionais não a contradigam (HESSE, 1993, p. 82) em ação ${ }^{23}$ e omissão ${ }^{24}$.

A vedação de medidas do Estado retrocessivas, no que diz respeito a direitos e garantias, impõe efeito prospectivo, com o intuito de que, no presente e no futuro, tenha-se, no mínimo, o mesmo nível de proteção e de promoção aos direitos e às garantias dos direitos sociais. Diante disso, não se deve descurar da visão de que a Constituição é um microssistema e compõe o macrossistema jurídico hierarquizado (FREITAS, 2010, p. 193, 200). Por consequência, as normas constitucionais e infraconstitucionais formam uma unidade coerente, que possui força normativa de diferentes graus. A interpretação jurídica deve levar em consideração essas características, inclusive no momento de fazer incidir o princípio de proibição de retrocesso conjuntamente com o princípio da solidariedade. Destacam-se o princípio da unidade da Constituição e o princípio da concordância prática das normas constitucionais (HESSE, 1993, p. 26-27).

É preciso reconhecer que os direitos fundamentais possuem posição privilegiada diante de outras normas constitucionais, justamente por ser vetor normativo-axiológico voltado à dignidade humana - fundamento do Estado de Direito brasileiro (PINTO E NETTO, 2010, p. 123). Destarte, em termos gerais, existe a preferência dos direitos fundamentais diante de outros direitos constitucionais. Soma-se a incidência da norma oriunda dos objetivos constitucionais, compondo o quadro normativo a recair sobre o caso concreto.

Nessa perspectiva, a proibição do retrocesso coaduna-se com a solidariedade, na medida

23 Vide: Brasil (2017) declara inconstitucionalidade de distinção de regime sucessório entre cônjuges e companheiros do Art. 1.790 do Código Civil.

24 Vide: Brasil (2014b). Tratam-se de políticas públicas não efetivadas pelo município de Belo Horizonte/MG. No mesmo sentido, mas contra o Estado-Membro: Brasil (2014a) e Brasil (2011). 
em que a última é elemento essencial em relação às questões sociais. Por meio da solidariedade e do não retrocesso de medidas, tem-se maior potencialização em medidas que privilegiam o desenvolvimento humano, criam-se pontes entre gerações e enfrentam os efeitos negativos da globalização (LORENZO, 2010, p. 146-149).

\subsection{Limites para analisar as restrições aos direitos sociais}

Os direitos sociais não são absolutamente irrestringíveis, porém não podem ter seu núcleo essencial reduzido ou abolido, sob pena de perder sua dimensão subjetiva e, com isso, a eficácia e a efetividade. Por consequência, pelo sistema de limite aos limites tem-se o seguinte: a) " a medida estatal que eventualmente restringe ou suprime um bem e/ou serviço protegido com base em direito social (fundamental) deve buscar atender finalidade constitucionalmente legítima" (SARLET; MARINONI; MITIDIERO, 2017, p. 621), por consequência, o fundamento constitucional deve ser forte o suficiente para restringir direito fundamental, ou seja, uma promoção ou proteção de outro direito fundamental ou interesse constitucionalmente relevante; b) a medida da imposição de restrição não deve reduzir ou suprimir o núcleo essencial do direito social; c) é necessária a observância dos parâmetros de proporcionalidade (quanto à proibição de excesso e à proteção insuficiente) e da razoabilidade; d) de acordo com o fato, no que couber, é preciso preservar as reservas legais, o conteúdo do princípio da segurança jurídica e observar os requisitos da proteção da confiança legítima (SARLET; MARINONI; MITIDIERO, 2017, p. 621); e) a medida estatal restritiva não deve contradizer, em seus efeitos práticos, os objetivos fundamentais do Estado brasileiro.

\subsection{Aplicação dos objetivos fundamentais}

A aplicação dos objetivos fundamentais, densificando o princípio da proibição de retrocesso social, acarreta um importante efeito, i.e., a dinâmica solidária a amenizar ou evitar o crescimento de mazelas sociais. Levando-se em consideração que os objetivos fundamentais são fórmulas políticas constitucionalizadas (normatizadas), retira-se a consequência de que toda a interpretação de efetivação de um texto jurídico (constitucional ou infraconstitucional) deva levar em consideração os objetivos fundamentais, sob pena de violá-los. Destarte, dentre as interpretações possíveis de um texto constitucional, a que deve prevalecer é aquela adequada aos valores dos objetivos constantes no Art. $3^{\circ} \mathrm{da}$ CF. Nota-se o rótulo de norma programática indique que elas são programas impostos ao Estado para que atue, continuamente, na concretização dos objetivos previstos. Contudo, são normas possuidoras de alta densidade normativa, na medida em que devem ser aplicadas de imediato a toda interpretação. Elas prescindem de qualquer tipo de complementação infraconstitucional (FREITAS, 2010, p. 200-201).

No caso da aplicação do princípio da solidariedade, Art. $3^{\circ}$, I, in fine, da $\mathrm{CF}$, qualquer conquista jurídico-social de aumento de solidariedade encontra-se adequada ao objetivo assinalado na norma constitucional. Identifica-se a concordância prática entre princípios (ZAGREBELSKY, 
2002, p. 124-125) e a necessidade de realizar um juízo de ponderação por parte do intérprete/ aplicador (FREITAS, 2010, p. 49). O inverso significa retrocesso social ou a redução das conquistas representa, juridicamente, a violação do objetivo imposto pelo legislador constituinte, por conseguinte, enfraqueceria a solidariedade. Destarte, o princípio do retrocesso social encontrase densificado por violação de norma constitucional e está vinculado à característica dirigente ou diretiva do estabelecido no Art. $3^{\circ}$ da CF. Portanto, prospectivamente, o princípio da solidariedade, conjuntamente com os demais objetivos fundamentais, exige que o Estado atue promovendo a solidariedade para que se alcance uma sociedade solidária. Obviamente, a não promoção da dinâmica da solidariedade no meio social não cumprirá com o objetivo do Art. $3^{\circ}$, I, da CF.

Ambos os princípios possuem consequências prospectivas. $\mathrm{O}$ que diz respeito à vedação de medidas retrocessivas que busca garantir, no presente e no futuro, a manutenção de conquistas no âmbito da concretização dos direitos sociais que fomentam a construção de uma sociedade solidária, as quais produzem reflexos na concretização da dignidade humana, princípio fundamental (Art. $1^{\circ}$, III, da CF). O princípio da solidariedade, vazado como objetivo fundamental, impõe aos Poderes, no presente e para o futuro, a construção de uma sociedade solidária, que se concretizará por intermédio da gradual efetividade dos direitos sociais até sua plena efetivação, não admitindo medidas retrocessivas.

\section{CONCLUSÃO}

O texto desenvolveu a possibilidade de densificação do princípio da proibição de retrocesso social, considerando incidência de um dos objetivos fundamentais contidos na Constituição de 1988. Tratou-se de uma abordagem de cunho analítico, com vistas a desenvolver a aplicação de dois princípios integrantes do ordenamento constitucional brasileiro, sendo um implícito e outro derivado de consequência lógica de comando normativo. É igualmente conhecido que a proibição de retrocesso social pode ser densificada por outros objetivos fundamentais incluídos nos demais incisos.

A consonância e a unicidade de ambos os princípios fazem com que a esfera normativa dos direitos sociais seja, necessariamente, valorizada, sob pena de inconstitucionalidades por regresso à omissão ou por redução de garantias mínimas, ligadas ao básico do mínimo existencial. Tal compreensão serve para garantir a concretização do princípio essencial dos fundamentos da chamada república brasileira, a dignidade humana. Sem a satisfação das necessidades básicas do ser humano, torna-se inviável a fruição dos direitos de liberdade (negativa e positiva).

Em consequência, um Estado de Direito social requer efetividade das garantias e dos direitos sociais. Ignorar esse fato significa ignorar o próprio Estado de Direito, por isso, tem-se, no princípio da proibição do retrocesso social, um sobreprincípio constitucional forjado no fogo das conquistas civilizacionais, ligadas à dignidade humana. Recuar ou retroceder nessas conquistas, é desvalorizar a dignidade humana e romper com a história do Estado de Direito constitucional.

Por outra senda, estando-se sob a égide de um Estado, pressupõe-se que se viva em sociedade e que, ao viver em sociedade, exista um mínimo de solidariedade entre os socii. O constituinte 
visualizou, portanto, a necessidade de se ter uma sociedade mais solidária e, por consequência, de regulamentar a norma de cunho programático e marcadamente dirigente que é o comando normativo construir uma sociedade mais solidária, o que significa fortalecer os direitos sociais. Enfraquecê-los é promover uma sociedade mais individualista e, por corolário, menos solidária. O resultado é/seria a violação do preceito constitucional.

Os dois princípios encontram-se em plena consonância de finalidades. Um complementa o outro, pois se o princípio da solidariedade exige maior extensão efetiva dos direitos sociais, o princípio da proibição do retrocesso impede que medidas retrocessivas, contrárias à dinâmica da solidariedade, possam se sobrepor aos direitos e às garantias existentes. Ademais, o princípio da solidariedade, como objetivo constitucional, fornece critérios interpretativos para a incidência do princípio da proibição do retrocesso. Assim, o aplicador do direito deve optar pela norma que ofereça maior grau de solidariedade, nesse caso, optar por dispositivos normativos e normas que ofereçam menor grau de solidariedade resulta em inconstitucionalidade e representa um retrocesso.

\section{REFERÊNCIAS}

ALEXY, Robert. Theorie der Grundrechte. Frankfurt am Main: Suhrkamp, 1994.

ANDRADE, José Carlos Vieira. Os direitos fundamentais na constituição portuguesa de 1976. Coimbra: Almedina, 1987.

APOSTOLI, Adriana. La svalutazione del principio di solidarietà. Crisi di um valore fondamentale per la democrazia. Milano: Giuffrè, 2012.

ÁVILA, Humberto. Segurança jurídica: entre permanência, mudança e realização no direito tributário. São Paulo: Malheiros, 2011.

BERCOVICI, Gilberto. Constituição econômica e desenvolvimento: uma leitura a partir da Constituição de 1988. São Paulo: Malheiros, 2005.

BRASIL. Decreto no 591, de 6 de julho de 1992. Atos Internacionais. Pacto Internacional sobre Direitos Econômicos, Sociais e Culturais. Promulgação. Brasília, DF: Presidência da República, 1992. Disponível em: http://www.planalto.gov.br/ccivil_03/decreto/1990-1994/d0591.htm. Acesso em: 5 jan. 2018.

BRASIL. Ag. Reg. No Recurso Extraordinário com Agravo 639.337. São Paulo, Segunda Turma. Agravante: Município de São Paulo. Agravado: Ministério Público do Estado de São Paulo. Relator: Ministro Celso de Mello. Julgado em 23 agosto de 2011. Disponível em: http:// redir.stf.jus.br/paginadorpub/paginador.jsp?docTP=AC\&docID=627428. Acesso em: 5 jan. 2018 .

\section{BRASIL. Supremo Tribunal Federal. Ag. Reg. No Recurso Extraordinário com Agravo}

727.864. Paraná. Segunda Turma. Agravante: Estado do Paraná. Agravado: Ministério Público do Estado do Paraná. Relator: Min. Celso de Mello. Julgado em: 4 novembro de 2014a. Disponível em: https://stf.jusbrasil.com.br/jurisprudencia/25311019/agreg-no-recurso-extraordinario-comagravo-are-727864-pr-stf/inteiro-teor-151223593. Acesso em: 9 jan. 2018.

BRASIL. Supremo Tribunal Federal. Ag. Reg. No Recurso Extraordinário com Agravo 
745.745. Minas Gerais. Segunda Turma. Agravante: Município de Belo Horizonte. Agravado: Ministério Público do Estado de Minas Gerais. Relator: Min. Celso de Mello. Julgado em 2 dezembro de 2014b. Disponível em: http://redir.stf.jus.br/paginadorpub/paginador. jsp?docTP=TP\&docID=7516923. Acesso em: 9 jan. 2018.

BRASIL. Supremo Tribunal Federal. Recurso Extraordinário 646.721. Rio Grande do Sul. Reclamante: São Martins Souza da Silva. Reclamado: Geni Quintana. Relator: Min. Marco Aurélio. Julgado em 10 maio 2017. Disponível em: https://stf.jusbrasil.com.br/ jurisprudencia/769815076/recurso-extraordinario-re-646721-rs-rio-grande-do-sul/inteiroteor-769815086. Acesso em: 9 jan.2018.

CANOTILHO, José Joaquim Gomes. "Brancosos" e interconstitucionalidade: itinerários dos discursos sobre a historicidade constitucional. Coimbra: Almedina, 2006.

CANOTILHO, José Joaquim Gomes. Constituição dirigente e vinculação do legislador: contributo para a compreensão das normas constitucionais programáticas. Coimbra: Coimbra, 1994.

CANOTILHO, José Joaquim Gomes. Direito constitucional e teoria da constituição. 5. ed. Coimbra: Almedina, 2002.

DERBLI, Felipe. O princípio da proibição de retrocesso social na constituição de 1988. Rio de Janeiro: Renovar, 2007.

FONTES, José. O direito ao quotidiano estável: uma questão de direitos humanos. Coimbra: Coimbra, 2013.

FRANÇA. Déclaration des Droits de I'Homme et du Citoyen de 1789. Paris: Conseil Constitutionnel, 1789. Disponível em: www.conseil-constitutionnel.fr/conseil-constitutionnel/ francais/la-constitution/la-constitution-du-4-octobre-1958/declaration-des-droit-de-1-homme-etdu-citoyen-de-1789.5076.html. Acesso em: 17 jan. 2018.

FREITAS, Juarez. A interpretação sistemática do direito. 5. ed. São Paulo: Malheiros, 2010.

GIUFFRÈ, Felice. La solidarietà nell'ordinamento costituzionale. Milano: Giuffrè, 2002.

HESSE, Konrad. Grundzüge des verfassungsrechts der Bundesrepublik deutschland. 19. ed. Heidelberg: Müller, 1993.

JASPERS, Karl. Wohin treibt die bundesrepublik? München: Piper, 1966.

KAUFMANN, Arthur. Gesetz und recht: festvortrag gehalten am 8. November 1961 anlasslich der feierlichen Eroffnung des Rektoratsjahres 1961/62. Saarbrücker: Universitätsreden, 1966.

LEITE, Carlos Henrique Bezerra. Comentário ao artigo 37, VII. In: CANOTILHO, José J. Gomes; MENDES, Gilmar F.; SARLET, Ingo W; STRECK, Lenio L. (coord.). Comentário à Constituição do Brasil. São Paulo: Saraiva: Almedina, 2013. p. 840-850.

LORENZO, Wambert Gomes Di. Teoria do estado de solidariedade: da dignidade da pessoa humana aos seus princípios corolários. Rio de Janeiro: Elsevier, 2010. 
LUZZATI, Claudio. La vaghezza delle norme. Un'analisi del linguaggio giuridico. Milano: Giuffrè, 1990.

MASSAÚ, Guilherme. O princípio republicano constituinte do mundo-da-vida do estado constitucional cosmopolita. Ijuí: Unijuí, 2016.

NOVAIS, Jorge Reis. A dignidade da pessoa humana: dignidade e direitos fundamentais. Coimbra: Almedina, 2015. v. 1.

PIAZOLO, Michael. Solidarität. Deutungen zu einem leitprinzip der europäischen union. Würzburg: Ergon, 2004.

PINTO E NETTO, Luísa Cristina. O princípio de proibição de retrocesso social. Porto Alegre: Livraria do Advogado, 2010.

SACHS, Michael. Verfassungsrecht II grundrecht. Berlin-Heidelberg: Springer, 2000.

SARLET, Ingo W.; BRANDÃO, Rodrigo. Comentário ao artigo 60. In: CANOTILHO, José J. Gomes; MENDES, Gilmar F.; STRECK, Lenio L. (coord.). Comentário à Constituição do Brasil. São Paulo: Saraiva: Almedina, 2013. p. 1124-1138.

SARLET, Ingo Wolfgang. A eficácia dos direitos fundamentais: uma teoria geral dos direitos fundamentais na perspectiva constitucional. 12. ed. Porto Alegre: Livraria do Advogado, 2015.

SARLET, Ingo Wolfgang. O Estado social de direito, a proibição de retrocesso e a garantia fundamental da propriedade. Revista da Faculdade de Direito da UFRGS, Porto Alegre, v. 17, p. 111-132, 1999.

SARLET, Ingo Wolfgang; MARINONI, Luiz Guilherme; MITIDIERO, Daniel. Curso de direito constitucional. 6. ed. São Paulo: Saraiva, 2017.

SCHOLZ, Sally J. Solidarity as a human rights. Archiv des Völkerrechts, Tübingen, p. 49-67, 2014.

SILVA, Suzana Tavares. Direitos fundamentais na arena global. Coimbra: Imprensa da Universidade de Coimbra, 2011.

VERDÚ, Pablo Lucas. O sentimento constitucional: aproximação ao estudo do sentir constitucional como modo de integração política. Tradução de Agassiz Almeida Filho. Rio de Janeiro: Forense, 2004.

VOLÄNDER, Hans. Die verfassung: idee und geschichte. München: C.H.Beck, 1999.

ZAGREBELSKY, Gustavo. El derecho dúctil. Ley, derechos, justicia. Tradução de Marina Gascón. 4. ed. Madrid: Trotta, 2002.

ZOLL, Rainer. Was ist solidarität heute? Frankfurt am Main: Suhrkamp, 2000.

Como citar: MASSAÚ, Guilherme Camargo. Princípio da solidariedade como critério de aplicação 
do princípio de proibição de retrocesso social em relação aos direitos sociais. Scientia Iuris, Londrina, v. 25, n. 1, p. 109-127, mar. 2021. DOI: 10.5433/21788189.2021v25n1p109. ISSN: 2178-8189.

Recebido em 27/11/2019

Aprovado em 02/12/2020 